\title{
When and how do patients with cardiac amyloidosis die?
}

\author{
F. Escher ${ }^{1,2} \cdot$ M. Senoner ${ }^{1} \cdot$ J. Doerler ${ }^{1} \cdot$ M. M. Zaruba ${ }^{1} \cdot$ M. Messner ${ }^{1} \cdot$ C. Mussner-Seeber ${ }^{1} \cdot$ M. Ebert ${ }^{1} \cdot$ C. Ensinger ${ }^{3}$. \\ A. Mair ${ }^{4} \cdot$ A. Kroiss ${ }^{5} \cdot$ H. Ulmer ${ }^{6} \cdot$ S. Schneiderbauer-Porod ${ }^{7}$. C. Ebner ${ }^{6} \cdot$ G. Poelzl ${ }^{1}$
}

Received: 11 January 2019 / Accepted: 7 May 2019 / Published online: 27 May 2019

(c) The Author(s) 2019

\begin{abstract}
Background Cardiac amyloidosis (CA) is an underappreciated cause of morbidity and mortality. Light-chain (AL) and transthyretin (ATTR) amyloidosis have different disease trajectories. No data are available on subtype-specific modes of death (MOD) in patients with CA.

Methods and results We retrospectively investigated 66 with AL and 48 with wild-type ATTR amyloidosis (ATTRwt) from 2000 to 2018 . ATTRwt differed from AL by age (74.6 \pm 5.4 years vs. $63 \pm 10.8$ years), posterior wall thickness $(16.8 \pm 3.3 \mathrm{~mm}$ vs. $14.3 \pm 2.2 \mathrm{~mm})$, left ventricular mass index $\left(180.7 \pm 63.2 \mathrm{~g} / \mathrm{m}^{2} \mathrm{vs} .133 .5 \pm 42.2 \mathrm{~g} / \mathrm{m}^{2}\right)$, and the proportions of male gender (91.7\% vs. 59.1\%), atrial enlargement (92\% vs. $68.2 \%$ ) and atrial fibrillation (50\% vs. $12.1 \%$ ). In AL NYHA Functional Class and proteinuria $(72.7 \%$ vs. $39.6 \%)$ were greater; mean arterial pressure $(84.4 \pm 13.5 \mathrm{mmHg}$ vs. $90.0 \pm 11.3 \mathrm{mmHg})$ was lower. Unadjusted 5-year mortality rate was $65 \%$ in AL-CA vs. $44 \%$ in the ATTRwt group. Individuals with AL-CA were 2.28 times ([95\%CI 1.27-4.10]; $p=0.006)$ more likely to die than were individuals with ATTRwt-CA. Information on MOD was available in $56(94.9 \%)$ of 59 deceased patients. MOD was cardiovascular in $40(66.8 \%)$ and non-cardiovascular in $16(27.1 \%)$ patients. Cardiovascular [28 (68.3\%) vs. 13 (80\%)] death events were distributed equally between AL and ATTRwt $(p=0.51)$.

Conclusion Our data indicate no differences in MOD between patients with AL and ATTRwt cardiac amyloidosis despite significant differences in clinical presentation and disease progression. Cardiovascular events account for more than twothirds of fatal casualties in both groups.
\end{abstract}

F. Escher and G. Poelzl contributed equally to this manuscript.

G. Poelzl

gerhard.poelzl@tirol-kliniken.at

1 Clinical Division of Cardiology and Angiology, Medical University of Innsbruck, Anichstrasse 35, 6020 Innsbruck, Austria

2 Department of Cardiology, LMU Munich, Munich, Germany

3 Department of Pathology, Medical University of Innsbruck, Innsbruck, Austria

4 Department of Radiology, Medical University of Innsbruck, Innsbruck, Austria

5 Department of Nuclear Medicine, Medical University of Innsbruck, Innsbruck, Austria

6 Department of Medical Statistics, Informatics and Health Economics, Medical University of Innsbruck, Innsbruck, Austria

7 Department of Cardiology, Ordensklinikum Elisabethinen Linz, Linz, Austria 


\section{Graphic abstract}

\section{When and how do patients with cardiac amyloidosis die?}

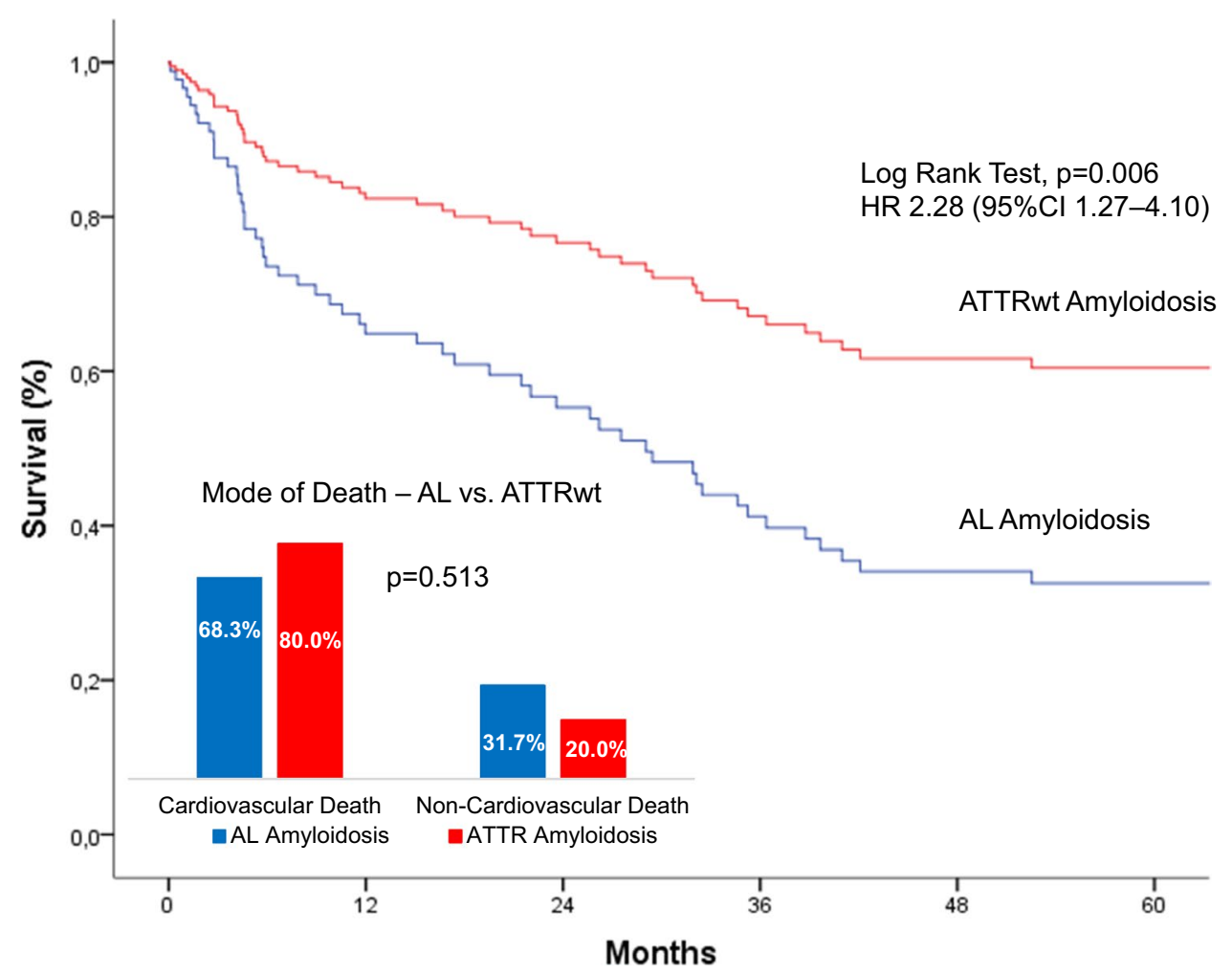

Keywords Cardiac amyloidosis $\cdot$ Light chain (AL) amyloidosis $\cdot$ Transthyretin (ATTR) amyloidosis $\cdot$ Prognosis $\cdot$ Mode of death

\section{Introduction}

Cardiac amyloidosis is an infiltrative process of the extracellular matrix that increases myocardial wall thickness in the absence of actual cardiomyocyte hypertrophy [1]. Acquired monoclonal immunoglobulin light-chain amyloidosis (AL), the hereditary, transthyretin (TTR)-related form (ATTRm), and wild-type (non-mutant) TTR-related amyloidosis (ATTRwt) systemic "senile" amyloidosis account for more than $90 \%$ of all cardiac amyloidosis (CA) [2].

While AL is considered a rare disease [3] and ATTRm is mostly seen in endemic regions [4] and in elderly patients of African descent [5], recent evidence suggests that ATTRwt is probably much more common than widely appreciated. ATTR was evident in patients with heart failure with preserved ejection fraction (HFpEF) [6] and in elderly patients with aortic stenosis [10]. In Finland, ATTR was found in $25 \%$ of autopsies in very old persons [11], giving rise to the suspicion that ATTRwt could be the most frequent form of CA [9].
AL typically affects multiple organ systems. Cardiac involvement is found in up to $70 \%$ of cases. While frequency of cardiac amyloidosis (CA) in ATTRm is variable and depends on the specific mutation [12], ATTRwt almost exclusively affects the heart. CA is typically associated with heart failure and dictates the clinical course of the disease. Most importantly, disease profiles and clinical courses differ between AL and ATTR [2, 13]. Prognosis is poor in patients with CA with better survival in ATTR than in AL $[2,8,13,14]$. Also, the two subtypes of CA differ significantly with respect to treatment options [8, 15].

A major limitation observed in the previously published literature is the fact that despite the commonly held notion that death in CA occurs either as a result of progressive heart failure or sudden cardiac death [16], mode of death in patients with cardiac AL and TTR amyloidosis has hardly been studied so far [17].

It was the aim of this comprehensive retrospective study to provide data on disease progression and mode of death in patients with cardiac AL and TTR amyloidosis 
to improve clinical management and service provision in these patients.

\section{Methods}

The study cohort consisted of consecutive patients with confirmed AL or ATTRwt amyloidosis seen between May 2000 and June 2018 at a tertiary (Cardiology Department, Medical University of Innsbruck) and a secondary (Cardiology Department, Ordensklinikum Elisabethinen Linz) centre. A comprehensive baseline assessment was performed in all patients including initial clinical evaluation and follow-up as well as laboratory, electrocardiographic, and echocardiographic parameters. Informed consent was waived due to the retrospective nature of the trial. The study was approved by the ethics committee of the Medical University of Innsbruck.

\section{Diagnostic definition}

Diagnosis of systemic amyloidosis was defined by histological documentation of Congo Red staining and apple-green birefringence under cross-polarized light in at least one involved organ. Cardiac amyloidosis was diagnosed either by means of endomyocardial biopsy (EMB), cardiac imaging [echocardiography, cardiac magnetic resonance (CMR) or 99mTC-3,3-diphosphono-1,2-propanodicarboxyl acid (99mTC-DPD) scintigraphy] and/or elevation of biomarkers (N-terminal pro brain natriuretic peptide, troponin $\mathrm{T}$ ) in patients with a positive result of non-cardiac biopsy [2, 18-20].

Diagnosis of ATTRm was defined by a documented TTR mutation at DNA analysis, ATTRwt by positive immunohistochemistry for TTR in the absence of any TTR mutation and AL by the presence of monoclonal plasma cells in the bone marrow. The Mayo staging system was used for risk stratification in AL and TTR amyloidosis using different cutoff values for troponin T and NT-proBNP for each subtype $[21,22]$.

\section{Data collection and definitions}

Follow-up was closed in June 2018. For patients who had not attended a follow-up in the last 3 months, vital status was ascertained by telephone contact and/or by contacting referring physicians. Information on death was retrieved from patients' charts, family doctors and relatives, and official documents of death. All deaths were adjudicated by two senior cardiologists (C. E. and G. P.). We employed a classification system derived from the "ACME system" for death in heart failure [23]. Mode of death (MOD) was first categorized as cardiovascular (CV) or non-cardiovascular (non-CV). CV deaths were subsequently classified as cardiac (sudden cardiac death [SCD] or circulatory failure) or vascular (stroke and "other" CV deaths including peripheral vascular disease, pulmonary embolism, mesenteric infarction, and procedural complications). SCD and circulatory failure comprising cardiogenic shock, pulmonary oedema and acute heart failure were defined according to established criteria [24].

\section{Statistical analysis}

Continuous data were tested for normal distribution using the Kolmogorov-Smirnov test. Categorical variables are presented as percentage (\%), continuous variables as mean [standard deviation (SD)] or median (25th, 75 th percentile). Between-group comparisons were performed with the $\mathrm{T}$ test, Mann-Whitney $U$ test or Pearson's Chi-squared test, as appropriate.

Survival analysis was performed for the AL and the ATTRwt amyloid subtypes with all-cause mortality as the endpoint. Patients were censored on June 30, 2018. The unadjusted association between amyloid subtypes and mortality was assessed using a univariable Cox proportional hazards model. Hazard ratios, 95\% CIs and $p$ values were calculated. A multivariable Cox model adjusted for age and sex was developed by selecting variables that were clinically relevant. Cardiovascular and non-cardiovascular modes of death were compared between groups with Fisher's exact test.

A two-sided $p$ value of 0.05 was considered to be statistically significant. All calculations were performed using the SPSS statistical package, version 23.0 (SPSS Inc., Chicago, IL, USA).

\section{Results}

A total of 124 patients with amyloidosis were screened for inclusion (Fig. 1). Three patients were excluded because of a transthyretin mutation; in seven patients, cardiac involvement could not be demonstrated. The final study cohort consisted of 114 patients: 66 with AL and 48 with ATTRwt amyloidosis. Diagnosis in ATTRwt was based on EMB in $94 \%$ and 99 mTC-DPD scintigraphy in $6 \%$ of patients, and in $\mathrm{AL}$ patients on EMB in $62.1 \%$ and on non-cardiac biopsy in $37.9 \%$. In those in whom the diagnosis was reached by non-cardiac biopsy, definition of cardiac involvement was based on echocardiography and/or CMR plus elevations of biomarkers.

AL amyloidosis was associated with multiple myeloma in $41(62 \%)$ and Waldenström's macroglobulinemia in 25 (38\%) patients.

Baseline characteristics of AL vs. ATTRwt for the total population are shown in Table 1. 


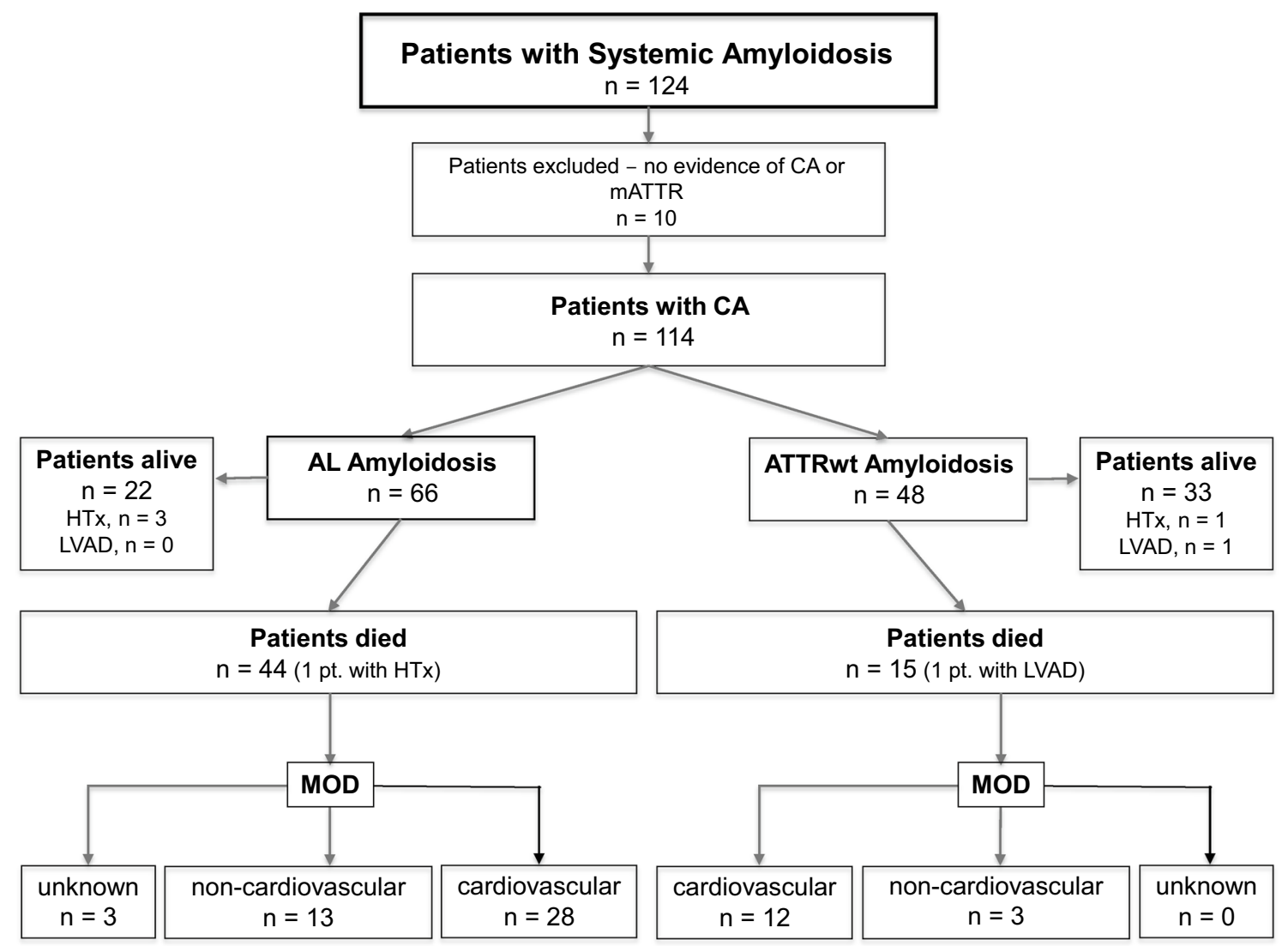

Fig. 1 Assembly of the cohort, participant flow, and mode of death in deceased patients. $C A$ cardiac amyloidosis, $H T x$ heart transplantation, $L V A D$ left ventricular assist device, $M O D$ mode of death

\section{Mortality and mode of death}

Overall, 325.7 patient years of follow-up were registered. Median follow-up for the entire cohort was 21.1 months (5.6-54.4). The group of patients with an AL subtype had a median follow-up of 16 months (4.6-60.9), while the ATTRwt cohort had a median follow-up of 24.6 months (6.8-50.6) $(p=0.81)$.

After censoring follow-up, 59 (51.8\%) of all patients met the endpoint of all-cause mortality. Of the patients with AL amyloidosis 44 died, corresponding to an unadjusted 5-year mortality rate of $65 \%$, while in the ATTRwt group there were 15 deaths, corresponding to a 5-year mortality rate (25.0\% 30-month mortality rate). Four patients received a heart transplant, three in the AL and one in the ATTRwt group, and one patient with TTR amyloidosis a LV assist device over the course of the study period.

Baseline characteristics of non-survivors vs. survivors are shown in Table 2. Deceased patients presented with higher NT-proBNP levels $(p=0.003)$ and higher NYHA functional class $(p=0.039)$. Interestingly, the proportion of patients in atrial fibrillation was significantly larger in survivors $(p=0.023)$. The Mayo score was not different between groups $(p=0.287)$. This was also true when AL and ATTRwt patients were analysed separately $(p=0.154$ and $p=0.764$, respectively).

Cox regression analysis showed individuals with $\mathrm{AL}$ amyloidosis to be 2.28 times ([95\% CI 1.27-4.10]; $p=0.006$ ) more likely to die than were individuals with ATTRwt amyloidosis (Fig. 2). Likewise, the combined endpoint of death, heart transplantation or LV assist device implantation was significantly higher in AL patients (HR 2.01 [95\% CI 1.22-3.83]; $p=0.008$ ). Multivariate Cox regression analysis adjusted for sex and age demonstrated that AL amyloid-specific subtype and lnNT-proBNP were associated with mortality independent of LV-EF, MAP, NYHA functional class, atrial fibrillation, and eGFR (Table 3). Results remained robust when in a subgroup of patients $(n=92)$ the Mayo staging score was added to the model.

Information on MOD was available for 56 (94.9\%) of the deceased patients. Of the deceased patients 37 (62.7\%) died in hospital, death was witnessed in another 9 (15.3\%) patients. Autopsy was performed in 13 (22.0\%) patients. Overall, MOD in (Fig. 3) was found to be CV in $40(67.8 \%)$ and non-CV in $16(27.1 \%)$ patients [sepsis in $4(6.8 \%)$, pneumonia in $3(5.1 \%)$, uraemia in $2(3.4 \%)$, GI 
Table 1 Patient baseline and treatment characteristics

\begin{tabular}{|c|c|c|c|c|}
\hline & $\begin{array}{l}\text { All Patients } \\
(n=114)\end{array}$ & $\begin{array}{l}\mathrm{AL} \\
(n=66)\end{array}$ & $\begin{array}{l}\text { ATTRwt } \\
(n=48)\end{array}$ & $p$ value \\
\hline \multicolumn{5}{|l|}{ Demographics } \\
\hline Sex (male) & $83(72.8)$ & $39(59.1)$ & $44(91.7)$ & $<0.001$ \\
\hline Age (years) & $67.8 \pm 10.6$ & $63.0 \pm 10.8$ & $74.6 \pm 5.4$ & $<0.001$ \\
\hline BMI $\left(\mathrm{kg} / \mathrm{m}^{2}\right)$ & $25.1 \pm 3.9$ & $24.5 \pm 4.1$ & $25.9 \pm 3.5$ & 0.054 \\
\hline \multicolumn{5}{|l|}{ Diagnosis of CA } \\
\hline Echocardiography & $114(100)$ & $66(100)$ & $48(100)$ & 1.000 \\
\hline Cardiac MRI & $81(71.1)$ & $44(66.7)$ & $39(76.4)$ & 0.509 \\
\hline DPD-Tc scintigraphy & $14(12.3)$ & $5(7.6)$ & $9(18.8)$ & 0.088 \\
\hline Endomyocardial biopsy & $86(75.4)$ & $41(62.1)$ & $45(93.75)$ & $<0.001$ \\
\hline Extracardiac biopsies & $25(21.9)$ & $25(37.9)$ & $0(0)$ & $<0.001$ \\
\hline \multicolumn{5}{|l|}{ Cardiac characteristics } \\
\hline NYHA functional class & & & & 0.047 \\
\hline I & $11(9.7)$ & $6(9.1)$ & $5(10.4)$ & \\
\hline II & $51(44.7)$ & $24(36.4)$ & $27(56.3)$ & \\
\hline III/IV & $52(45.6)$ & $36(54.5)$ & $16(33.3)$ & \\
\hline Mayo staging score ${ }^{\mathrm{a}}$ & & & & 0.547 \\
\hline I & $3(3.3)$ & $2(3.5)$ & $1(2.9)$ & \\
\hline II & $23(25.0)$ & $12(21.1)$ & $11(31.4)$ & \\
\hline III & $66(71.7)$ & $43(75.4)$ & $23(65.7)$ & \\
\hline MAP (mmHg) & $86.7 \pm 12.9$ & $84.4 \pm 13.5$ & $90.0 \pm 11.3$ & 0.018 \\
\hline $\mathrm{CAD}^{*}$ & $20(17.7)$ & $10(15.2)$ & $10(20.8)$ & 0.458 \\
\hline Valvular heart disease $\mathrm{b}^{\mathrm{b}}$ & $11(9.6)$ & $8(12.1)$ & $3(6.3)$ & 0.352 \\
\hline NTpro-BNP (ng/L) & $4578 \pm 4378$ & $5141 \pm 5300$ & $3873 \pm 2730$ & 0.543 \\
\hline Cardiac troponin $\mathrm{T}(\mathrm{ng} / \mathrm{L})^{\mathrm{c}}$ & $77.6 \pm 70.4$ & $86.8 \pm 84.4$ & $62.3 \pm 32.3$ & 0.673 \\
\hline \multicolumn{5}{|l|}{ Echocardiography } \\
\hline Atrial enlargement & $88(77.2)$ & $45(68.2)$ & $43(89.6)$ & 0.005 \\
\hline LV-EF (\%) & $51.5 \pm 11.4$ & $53.6 \pm 11.4$ & $48.7 \pm 11.1$ & 0.020 \\
\hline PWD, mm & $15.4 \pm 3.0$ & $14.3 \pm 2.2$ & $16.8 \pm 3.3$ & $<0.001$ \\
\hline LV mass (g) & $281.3 \pm 108.9$ & $247.0 \pm 90.6$ & $331.0 \pm 114.8$ & $<0.001$ \\
\hline LV mass index $\left(\mathrm{g} / \mathrm{m}^{2}\right)$ & $152.4 \pm 56.3$ & $133.5 \pm 42.2$ & $180.7 \pm 63.2$ & $<0.001$ \\
\hline $\mathrm{E} / \mathrm{A}$ ratio & $1.81 \pm 1.22$ & $1.68 \pm 1.04$ & $2.15 \pm 1.64$ & 0.457 \\
\hline Pericardial effusion & $38(33.3)$ & $24(36.4)$ & $14(29.2)$ & 0.220 \\
\hline \multicolumn{5}{|l|}{ ECG } \\
\hline Atrial fibrillation & $32(28.1)$ & $8(12.1)$ & $24(50.0)$ & $<0.001$ \\
\hline First-degree AV-block & $24(21.1)$ & $7(10.6)$ & $17(35.4)$ & 0.002 \\
\hline Third-degree AV-block & $3(2.6)$ & $2(3.0)$ & $1(2.1)$ & 1.0 \\
\hline Low voltage signs & $23(20.2)$ & $18(27.3)$ & $5(10.4)$ & 0.032 \\
\hline Pseudoinfarct pattern & $29(25.4)$ & $15(22.7)$ & $14(29.2)$ & 0.520 \\
\hline \multicolumn{5}{|l|}{ Renal characteristics } \\
\hline Creatinine (mg/dl) & $1.26 \pm 0.71$ & $1.24 \pm 0.90$ & $1.28 \pm 0.29$ & 0.008 \\
\hline eGFR (ml/min) & $62.4 \pm 22.4$ & $66.8 \pm 25.6$ & $56.3 \pm 15.4$ & 0.007 \\
\hline Proteinuria & $67(58.8)$ & $48(72.7)$ & $19(39.6)$ & 0.001 \\
\hline \multicolumn{5}{|l|}{ Specific therapy } \\
\hline Immunotherapy & & $53(80.3)$ & & $\mathrm{n} / \mathrm{a}$ \\
\hline Chemotherapy & & $56(84.0)$ & & $\mathrm{n} / \mathrm{a}$ \\
\hline ASCT & & $14(21.2)$ & & $\mathrm{n} / \mathrm{a}$ \\
\hline Green tea capsules/EGCG & $23(20.2)$ & $6(9.1)$ & $17(35.4)$ & $<0.001$ \\
\hline Tafamidis & & & $3(5.9)$ & $\mathrm{n} / \mathrm{a}$ \\
\hline Anticoagulant therapy & $75(65.8)$ & $40(60.6)$ & $35(72.9)$ & 0.158 \\
\hline ICD & $11(9.6)$ & $4(6.1)$ & $7(14.6)$ & 0.198 \\
\hline
\end{tabular}


Table 1 (continued)

\begin{tabular}{lllll}
\hline & $\begin{array}{l}\text { All Patients } \\
(n=114)\end{array}$ & $\begin{array}{l}\text { AL } \\
(n=66)\end{array}$ & $\begin{array}{l}\text { ATTRwt } \\
(n=48)\end{array}$ & $p$ value \\
\hline Pacemaker & $18(15.8)$ & $8(12.1)$ & $10(20.8)$ & 0.298 \\
HTx/LVAD & $5(4.4)$ & $3(4.5)$ & $2(4.2)$ & 0.637 \\
\hline
\end{tabular}

Data from 114 patients are reported as mean ( \pm standard deviation) or number (percentage)

$B M I$ body mass index, NYHA New York heart association, MAP mean atrial pressure pressure, $C A D$ coronary artery disease, $N T$-proBNP N-terminal pro-B-type natriuretic peptide, $L V$ - $E F$ left ventricular ejection fraction, Syst. $P W D$ posterior wall thickness, $e G F R$ estimated glomerular filtration rate, ASCT autologous stem cell transplantation, EGCG epigallocatechin gallate, ICD implantable cardioverter/defibrillator, $H T x$ heart transplantation, $L V A D$ left ventricular assist device

${ }^{a} \geq 70 \%$ stenosis a/o need for coronary intervention

${ }^{\mathrm{b}}$ Including severe aortic stenosis, mitral regurgitation/stenosis, and tricuspid regurgitation

${ }^{\mathrm{c}}$ Troponin $\mathrm{T}$ and Mayo staging score were available in 92 patients-different Mayo staging scores were applied for each subtype according to Dispenzieri et al. [21] and Grogan et al. [22]

bleeding in $2(3.4 \%)$, anaemia in $1(1.7 \%)$, accident in 1 $(1.7 \%)$, and cachexia in $3(5.1 \%)$ patients, respectively], but remained unknown in $3(5.1 \%)$ patients (AL) in the entire cohort. In deceased patients time to death was numerically, but not statistically, significantly shorter for CV [23.3 months (4.6-34.6)] compared with non-CV death events [26.8 months 4.7-34.0)] $(p=0.67)$. Almost all CV deaths were cardiac $(97.5 \%)$ and one was vascular due to cerebral hemorrhage).

Among patients with documented MOD, CV $[28$ (68.3\%) vs. $12(80.0 \%)$ ] and non-CV [13 (31.7\%) vs. $3(20.0 \%)]$ death events were distributed equally between AL and TTR subtypes ( $p=0.513$ ) (Fig. 3). Even when multi-organ failure (MOF) was considered non-CV, CV deaths still accounted for $61 \%$ in AL and $77.3 \%$ in TTR patients $(p=0.49)$. Also, there were no major differences between AL and TTR patients in terms of sudden cardiac death $[4(9.1 \%)$ vs. 0 $(0.0 \%)]$, cardiogenic shock [2 $(4.5 \%)$ vs. $0(0.0 \%)]$, acute heart failure [19 (43.2\%) vs. $10(66.7 \%)]$, MOF [3 (6.8\%) vs. 1 (6.7\%)], sepsis/pneumonia [5 (11.4\%) vs. $2(13.3 \%)$ ], uraemia [2 (4.5\%) vs. $0(0.0 \%)$ ], GI bleeding [1 (2.3\%) vs. 1 $(6.7 \%)$, anaemia [1 (2.3\%) vs. $0(0.0 \%)]$, accident [1 (2.3\%) vs. $0(0.0 \%)$ ], and cachexia [3 (6.8\%) vs. $0(0.0 \%)$ ] (Fig. 3).

\section{Discussion}

This study describes a well-characterized cohort of patients with cardiac amyloidosis. Our study shows that although clinical presentation and disease progression differed between AL and ATTRwt, CV death was the predominant mode of death in both subtypes.

Mortality was high in the entire cohort of patients. Prognosis was significantly worse in AL than in ATTRwt. This is well in line with previous studies in patients with CA [2, $8,13,14]$. Five-year mortality rate in our cohort was $65 \%$ in AL and $44 \%$ in TTR. The $25 \% 30$-month mortality rate in the ATTR group corresponds largely to the number reported in the recently published ATTR-ACT study [25]. Although non-survivors presented at baseline with more severe heart failure symptoms effects of the amyloid subtype on mortality were independent of substantial confounders including NT-proBNP levels. Mayo staging scores were not different between survivors and non-survivors.

Information on MOD was available in $95 \%$ of patients. Similar to previous reports concerning heart failure $[6,24]$ $2.7 \%$ of our patients died in hospital. Necropsy was performed in a minority (22\%) of patients. Interestingly, cardiovascular events accounted for more than two-thirds of fatal casualties in both groups. Circulatory failure comprising cardiogenic shock, acute heart failure and multi-organ failure was the predominant MOD. Thus, our data on MOD for the first time provide evidence for the predominance of $\mathrm{CV}$ deaths in patients with CA irrespective of the amyloid subtype, which was previously discussed in the literature [16]. MOD in our cohort of patients with cardiac amyloidosis agrees well with $60-70 \% \mathrm{CV}$ deaths and $20-30 \%$ non-CV deaths, which were recently reported in patients with $\mathrm{HFpEF}$ of various aetiologies [26].

Since information on circumstances of death was retrieved retrospectively, exact definition of cause of death (COD) was difficult to determine in a substantial number of the deceased. Therefore, we refrain from reporting separately on COD. In contrast, MOD was able to be defined in most patients. Due to the systemic nature of the disease in AL with concomitant involvement of several organ systems, adjudication of MOD was complex in patients with MOF. Nevertheless, if patients with MOF were classified non-CV instead of $\mathrm{CV}$, the proportion of circulatory failure events remained large. Acute heart failure was the main cause of $\mathrm{CV}$ deaths in AL and ATTRwt $(68.3 \%$ and $80 \%$, respectively). Similarity between groups in this regard is remarkable since first presentation of CA was different in both subtypes. The majority of ATTRwt patients presented 
Table 2 Baseline characteristics in survivors vs. non-survivors

\begin{tabular}{|c|c|c|c|}
\hline & $\begin{array}{l}\text { Survivors } \\
(n=55)\end{array}$ & $\begin{array}{l}\text { Non-survivors } \\
(n=59)\end{array}$ & $p$ value \\
\hline \multicolumn{4}{|l|}{ Demographic characteristics } \\
\hline Sex (male) & $42(76.4)$ & $41(69.5)$ & 0.528 \\
\hline Age (years) & $68.2 \pm 11.3$ & $67.5 \pm 10.0$ & 0.378 \\
\hline BMI $\left(\mathrm{kg} / \mathrm{m}^{2}\right)$ & $25.3 \pm 3.9$ & $24.9 \pm 3.8$ & 0.605 \\
\hline \multicolumn{4}{|l|}{ Cardiac characteristics } \\
\hline NYHA functional class & & & 0.039 \\
\hline I & $8(14.6)$ & $3(5.1)$ & \\
\hline II & $28(50.9)$ & $23(39.0)$ & \\
\hline III/IV & $19(34.5)$ & $33(55.9)$ & \\
\hline Mayo staging score ${ }^{a}$ & & & 0.287 \\
\hline I & $3(6.4)$ & $0(0.0)$ & \\
\hline II & $12(25.5)$ & $11(24.4)$ & \\
\hline III & $32(68.1)$ & 34 (75.6) & \\
\hline MAP $(\mathrm{mmHg})$ & $88.4 \pm 10.5$ & $85.2 \pm 14.6$ & 0.192 \\
\hline CAD* & $12(21.8)$ & $7(11.9)$ & 0.324 \\
\hline Valvular heart disease $^{\mathrm{b}}$ & $4(7.3)$ & $8(13.6)$ & 0.364 \\
\hline NTpro-BNP (ng/L) & $3569 \pm 3232$ & $5623 \pm 5137$ & 0.003 \\
\hline Cardiac troponin $\mathrm{T}(\mathrm{ng} / \mathrm{L})^{\mathrm{c}}$ & $72.5 \pm 61.5$ & $82.6 \pm 78.8$ & 0.665 \\
\hline \multicolumn{4}{|l|}{ Echocardiography } \\
\hline Atrial enlargement & $39(70.1)$ & $49(83.1)$ & 0.181 \\
\hline LV-EF & $52.9 \pm 11.1$ & $50.2 \pm 11.6$ & 0.235 \\
\hline PWD (mm) & $15.7 \pm 3.5$ & $15.1 \pm 2.5$ & 0.307 \\
\hline LV Mass (g) & $301.0 \pm 127.0$ & $266.0 \pm 90.0$ & 0.121 \\
\hline LV mass Index $\left(\mathrm{g} / \mathrm{m}^{2}\right)$ & $163.5 \pm 67.5$ & $143.9 \pm 44.7$ & 0.179 \\
\hline E/A ratio & $1.40 \pm 0.89$ & $2.05 \pm 1.34$ & 0.093 \\
\hline Pericardial effusion & $18(32.7)$ & $20(33.9)$ & 0.686 \\
\hline \multicolumn{4}{|l|}{ ECG } \\
\hline Atrial fibrillation & $21(38.2)$ & $11(18.6)$ & 0.023 \\
\hline AV-block & $15(27.3)$ & $12(20.3)$ & 0.508 \\
\hline First-degree AV-block & $14(25.4)$ & $10(16.9)$ & 0.358 \\
\hline Third-degree AV-block & $1(1.8)$ & $2(3.4)$ & 1.0 \\
\hline Pseudoinfarct patterns & $15(27.3)$ & $14(23.7)$ & 0.673 \\
\hline \multicolumn{4}{|l|}{ Renal characteristics } \\
\hline Creatinine (mg/dl) & $1.27 \pm 0.90$ & $1.25 \pm 0.48$ & 0.725 \\
\hline eGFR (ml/min) & $63.8 \pm 23.7$ & $61.1 \pm 21.3$ & 0.531 \\
\hline Proteinuria & $28(50.1 \%)$ & $39(66.1 \%)$ & 0.241 \\
\hline \multicolumn{4}{|l|}{ Specific therapy } \\
\hline Green tea capsules/EGCG & $10(18.2)$ & $13(22.0)$ & 0.645 \\
\hline Anticoagulant therapy & $35(63.6)$ & $40(67.8)$ & 0.842 \\
\hline ICD & $6(10.9)$ & $5(8.5)$ & 0.756 \\
\hline Pacemaker & $5(9.1)$ & $13(22.0)$ & 0.074 \\
\hline HTx/LVAD & $3(5.5)$ & $2(3.4)$ & 0.673 \\
\hline
\end{tabular}

Data from 114 patients are reported as mean ( \pm standard deviation) or number (percentage)

$B M I$ body mass index, NYHA New York heart association, MAP mean atrial pressure pressure, $C A D$ coronary artery disease, NTproBNP N-terminal pro-B-type natriuretic peptide, $L V$-EF left ventricular ejection fraction, Syst.; $P W D$ posterior wall thickness, $e G F R$ estimated glomerular filtration rate, $E G C G$ epigallocatechin gallate, $I C D$ implantable cardioverter/defibrillator, HTx heart transplantation, $L V A D$ left ventricular assist device

${ }^{\mathrm{a}} \geq 70 \%$ stenosis a/o need for coronary intervention

${ }^{\mathrm{b}}$ Including severe aortic stenosis, mitral regurgitation/stenosis, and
Table 2 (continued)

tricuspid regurgitation

${ }^{\mathrm{c}}$ Troponin $\mathrm{T}$ and Mayo staging score were available in 92 patients

with heart failure with preserved ejection fraction (HFpEF) characterized by greater $\mathrm{LV}$ mass and a larger percentage of atrial enlargement and atrial fibrillation compared to AL. In contrast, AL patients were younger with a female predominance, higher NYHA functional class and lower blood pressure, and a larger percentage of proteinuria. Discrepancies between groups in our cohort of CA patients are corroborated by comparable data from the existing literature $[2,7,13,14,27,28]$. It is speculated that differences in extracellular amyloid deposition and a likely toxic effect on cardiomyocytes and their architecture, as demonstrated in $\mathrm{AL}$ amyloidosis [29], account for differences in phenotypic appearance and - together with non-cardiological factorsalso for differences in mortality $[2,9]$.

In fact, our data show that heart failure is the predominant MOD in both subtypes despite significant differences in patient presentation and disease progression.

Interestingly, SCD was registered only in a minority of patients in both groups. It must be acknowledged that 25\% of our patients were treated with an ICD and/or pacemaker. However, no appropriate ICD discharge was documented in these patients. Indeed, previous studies could not show a survival benefit despite appropriate ICD shocks in patients with CA [30,31]. This was mostly attributed to electromechanical dissociation, as the underlying mechanism for SCD in CA.

The most common non-CV MOD in both subtypes was sepsis and pneumonia in $11.4 \%$ of AL and $13.3 \%$ of ATTRwt patients. The relatively small number in AL with the majority of patients treated with chemotherapy and/or autologous stem cell transplantation is contrary to common expectation. This phenomenon may indicate excellent oncologic patient management and emphasizes the need for interdisciplinary management of CA patients.

Of note, only one vascular death was registered in the entire cohort. This is remarkable as cardioembolic events and venous thromboembolism are frequent in amyloidosis [32]. In an early necropsy series, $26 \%$ of patients with CA had one or more cardiac chamber thrombi [33]. In our cohort, $28.2 \%$ of patients were in atrial fibrillation and thus particularly prone to cardioembolic events. It can be speculated that low incidence of deadly vascular events was due to a large percentage of patients on anticoagulant therapy in both subtypes. Intensive anticoagulant therapy, however, may have been penalized by three cases of deadly bleedings.

Importantly, disease prognosis has been altered with the development of new strategies that efficiently supress secretion of amyloid-forming light chains in AL and also with earlier diagnosis that may prevent irreversible damage to the 
Fig. 2 Correlation between cardiac AL and TTR amyloidosis and mortality Cumulative 5-year event rates estimated by univariate Cox proportional hazard regression analysis in 117 patients with cardiac amyloidosis according to subtype are presented. Numbers of patients at risk and event rates are shown below the graphs

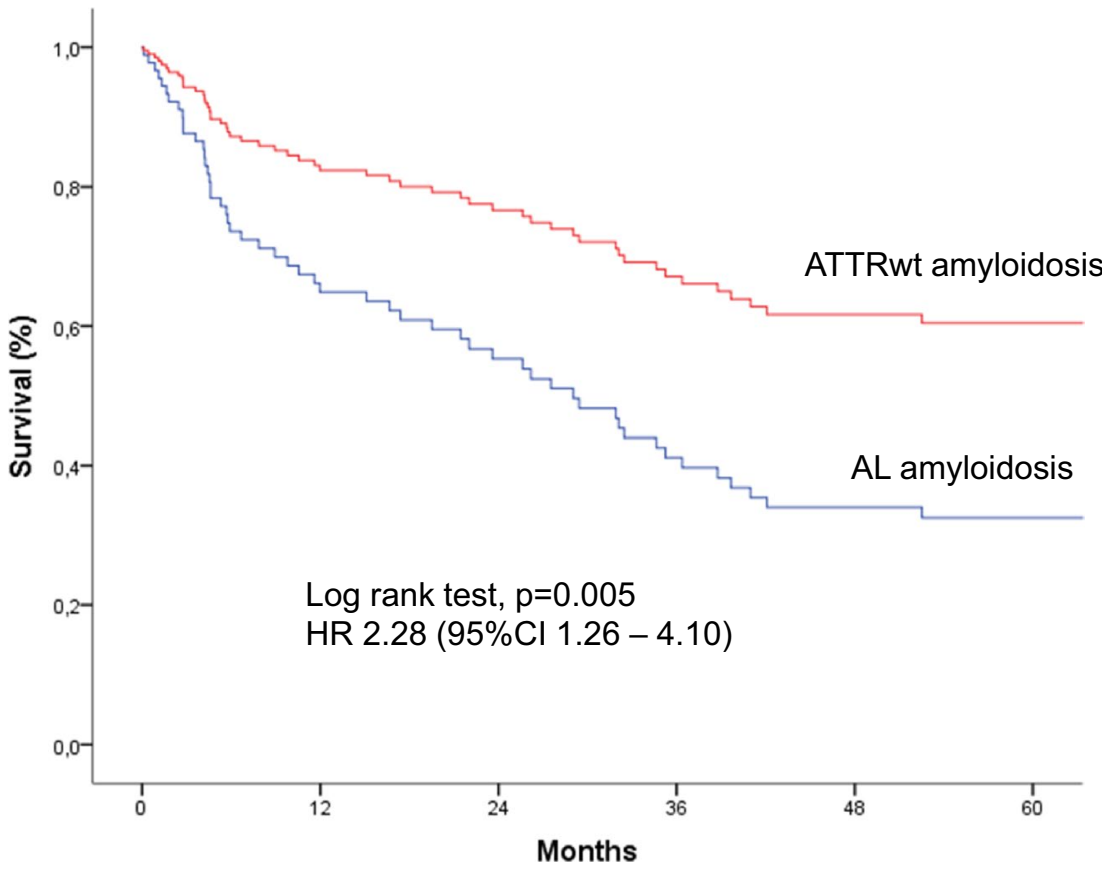

Number of patients at risk (cumulative proportion of mortality, \%)

$\begin{array}{llcllll}\text { AL amyloidosis } & 66 & 36(41) & 27(49) & 20(59) & 18(63) & 17(65) \\ \text { ATTR amyloidosis } & 48 & 32(7) & 24(14) & 19(32) & 18(44) & 13(44)\end{array}$

Table 3 Association between amyloidosis subtypes and survival during the observation period using multivariate, sex- and age-adjusted Cox proportional hazards regression analyses

\begin{tabular}{lcccc}
\hline & \multicolumn{3}{l}{$\begin{array}{l}\text { Multivariate model adjusted for age } \\
\text { and sex }\end{array}$} \\
\cline { 2 - 5 } & Wald & HR & $95 \%$ CI & $p$ value \\
\hline AL vs. ATTRwt & 7.02 & 3.03 & $1.33-6.87$ & 0.008 \\
LV-EF, per \% & 1.47 & 0.98 & $0.96-1.01$ & 0.225 \\
MAP, per mmHg & 0.75 & 0.99 & $0.97-1.01$ & 0.387 \\
NYHA class, overall & 0.64 & & & 0.728 \\
A-Fib, y/n & 0.59 & 0.71 & $0.30-1.67$ & 0.441 \\
lnNT-proBNP, per ln ng/L & 11.95 & 2.16 & $1.39-3.33$ & 0.001 \\
eGFR, per ml/min/1.73 m & 2.467 & 1.02 & $0.99-1.02$ & 0.116 \\
\hline
\end{tabular}

$L V$-EF left ventricular ejection fraction, NYHA New York Heart Association, MAP mean atrial pressure, A-Fib atrial fibrillation, $I n N T$ proBNP logarithmically transformed $\mathrm{N}$-terminal pro-B-type natriuretic peptide, $e G F R$ estimated glomerular filtration rate

heart $[8,15]$. Up to now, treatment in ATTRwt was limited mostly to supportive care. The recent emergence of novel therapeutics such as tafamidis [25], which act to prevent transthyretin amyloid formation, and other agents that inhibit transthyretin expression $[34,35]$ offers promise for the near future in the management of ATTRwt, which probably constitutes the majority of CA patients. This underscores even
Fig. 3 a, b Mode of death stratified by amyloid subtype. All deaths are divided into cardiovascular $(\mathrm{CV})$, non-CV, and unknown deaths; cardiovascular deaths are further subdivided into sudden cardiac death (SCD), cardiogenic shock, acute heart failure, cerebral haemorrhage, and multi-organ failure (MOF), while non-CV deaths are subdivided into sepsis/pneumonia, uraemia, GI bleeding, anaemia, accident, and cachexia

more the cardiologists' responsibilities with regard to early and exact diagnosis as well as comprehensive disease management strategies.

\section{Strengths and limitations}

Strengths of our study include the comprehensive clinical characterization and complete follow-up of our sample. However, some limitations apply to this study. Information on COD, which could not be retrieved in a substantial number of patients, would have improved the value of the study. MOD in ten patients whose dead was not witnessed and who had no autopsy was classified based on death records a/o information received from relatives concerning the last hours of the deceased individuals. No information was available on non-deadly strokes, heart failure admissions, and pacemaker dependency, which would have improved assessment of disease progression. 
(a) AL Amyloidosis

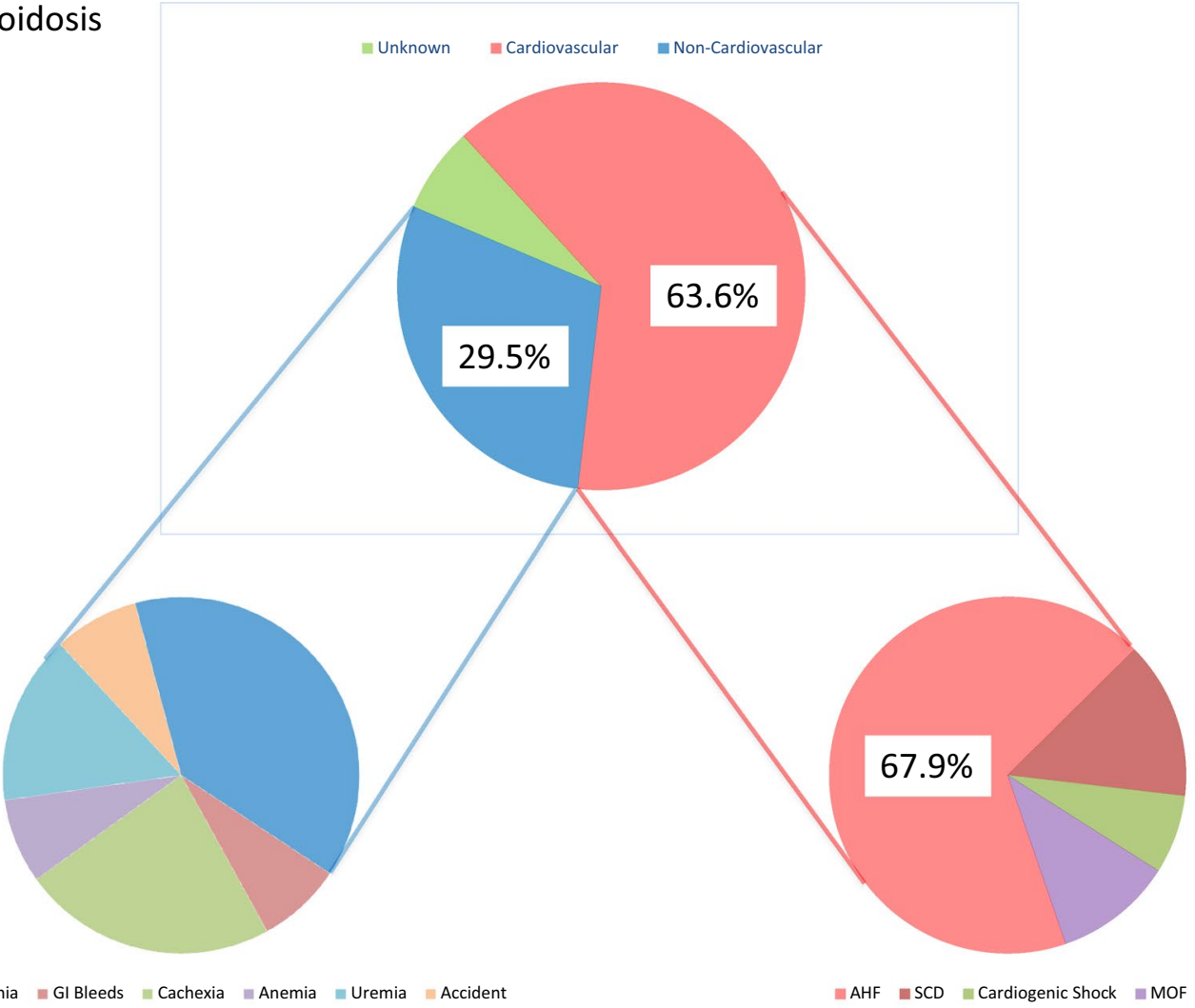

(b) ATTRwt Amyloidosis

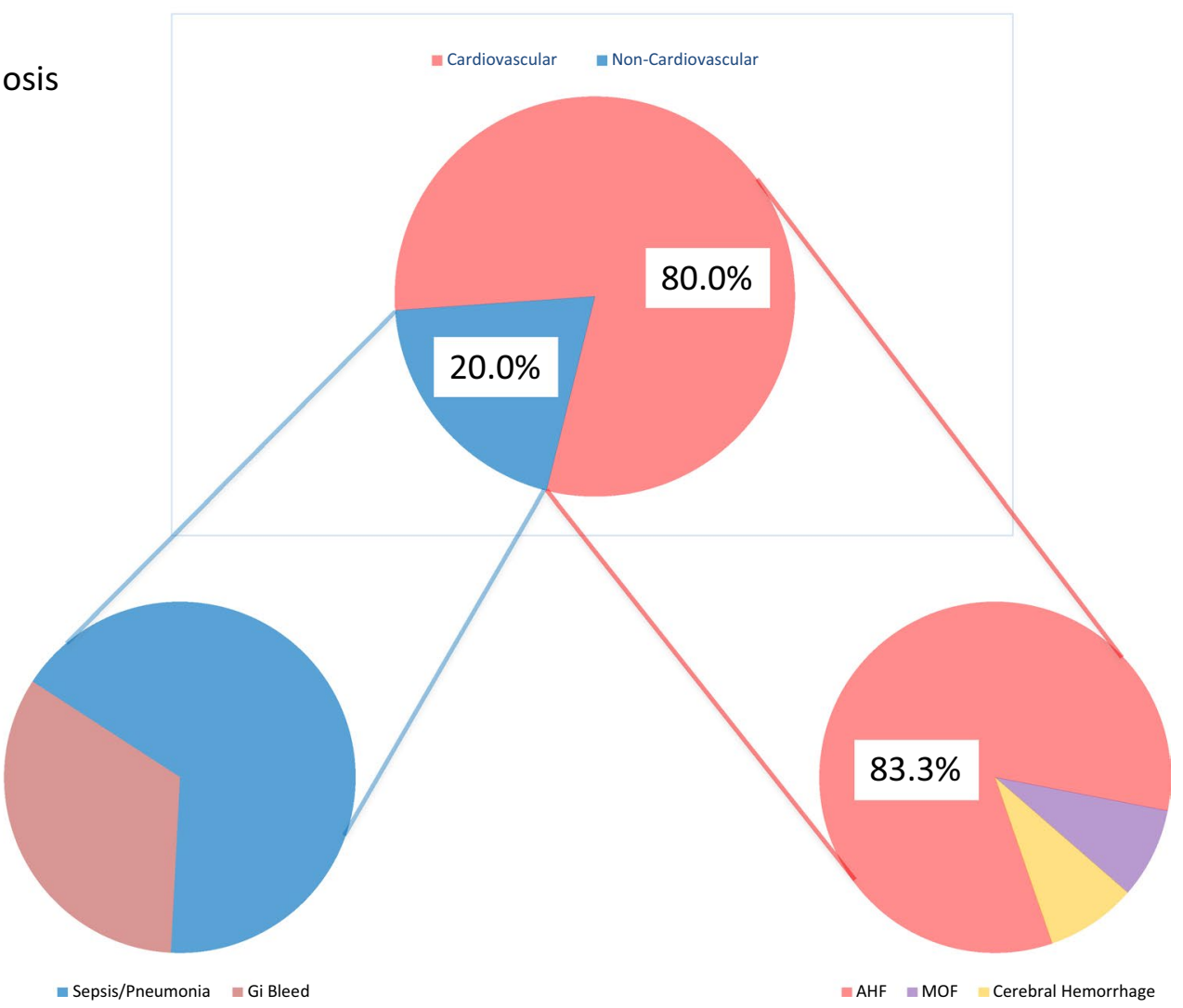




\section{Conclusions}

This analysis shows no differences in MOD between patients with AL and TTRwt cardiac amyloidosis despite significant differences in clinical presentation and disease progression. Cardiovascular events account for two-thirds of fatal causalities in both groups. Our findings underline the great responsibility of cardiologists in the management of CA and call for early diagnosis, meticulous fluid control to avoid congestion, and prevention or even reversal of disease progression by providing vigorous treatment of the underlying pathomechanism by an interdisciplinary team.

Acknowledgements Open access funding provided by University of Innsbruck and Medical University of Innsbruck. We thank Eva-Maria Stocker for her excellent support with endomyocardial biopsies.

Funding None.

\section{Compliance with ethical standards}

Conflict of interest Poelzl $\mathrm{G}$ has received speaker honoraria from Pfizer and AKCEA Therapeutics.

Open Access This article is distributed under the terms of the Creative Commons Attribution 4.0 International License (http://creativeco mmons.org/licenses/by/4.0/), which permits unrestricted use, distribution, and reproduction in any medium, provided you give appropriate credit to the original author(s) and the source, provide a link to the Creative Commons license, and indicate if changes were made.

\section{References}

1. Elliott P, Andersson B, Arbustini E, Bilinska Z, Cecchi F, Charron P, Dubourg O, Kuhl U, Maisch B, McKenna WJ, Monserrat L, Pankuweit S, Rapezzi C, Seferovic P, Tavazzi L, Keren A (2008) Classification of the cardiomyopathies: a position statement from the European Society Of Cardiology Working Group on Myocardial and Pericardial Diseases. Eur Heart J 29:270-276

2. Rapezzi C, Merlini G, Quarta CC, Riva L, Longhi S, Leone O, Salvi F, Ciliberti P, Pastorelli F, Biagini E, Coccolo F, Cooke RM, Bacchi-Reggiani L, Sangiorgi D, Ferlini A, Cavo M, Zamagni E, Fonte ML, Palladini G, Salinaro F, Musca F, Obici L, Branzi A, Perlini S (2009) Systemic cardiac amyloidoses: disease profiles and clinical courses of the 3 main types. Circulation 120:1203-1212

3. Pinney JH, Smith CJ, Taube JB, Lachmann HJ, Venner CP, Gibbs SD, Dungu J, Banypersad SM, Wechalekar AD, Whelan CJ, Hawkins PN, Gillmore JD (2013) Systemic amyloidosis in England: an epidemiological study. Br J Haematol 161:525-532

4. Dardiotis E, Koutsou P, Papanicolaou EZ, Vonta I, Kladi A, Vassilopoulos D, Hadjigeorgiou G, Christodoulou K, Kyriakides $\mathrm{T}$ (2009) Epidemiological, clinical and genetic study of familial amyloidotic polyneuropathy in Cyprus. Amyloid 16:32-37

5. Damy T, Costes B, Hagege AA, Donal E, Eicher JC, Slama M, Guellich A, Rappeneau S, Gueffet JP, Logeart D, Plante-Bordeneuve V, Bouvaist H, Huttin O, Mulak G, Dubois-Rande JL, Goossens M, Canoui-Poitrine F, Buxbaum JN (2016) Prevalence and clinical phenotype of hereditary transthyretin amyloid cardiomyopathy in patients with increased left ventricular wall thickness. Eur Heart J 37:1826-1834

6. Mohammed SF, Mirzoyev SA, Edwards WD, Dogan A, Grogan DR, Dunlay SM, Roger VL, Gertz MA, Dispenzieri A, Zeldenrust SR, Redfield MM (2014) Left ventricular amyloid deposition in patients with heart failure and preserved ejection fraction. JACC Heart Fail 2:113-122

7. Gonzalez-Lopez E, Gallego-Delgado M, Guzzo-Merello G, de Haro-Del Moral FJ, Cobo-Marcos M, Robles C, Bornstein B, Salas C, Lara-Pezzi E, Alonso-Pulpon L, Garcia-Pavia P (2015) Wild-type transthyretin amyloidosis as a cause of heart failure with preserved ejection fraction. Eur Heart J 36:2585-2594

8. Gertz MA, Benson MD, Dyck PJ, Grogan M, Coelho T, Cruz M, Berk JL, Plante-Bordeneuve V, Schmidt HHJ, Merlini G (2015) Diagnosis, prognosis, and therapy of transthyretin amyloidosis. J Am Coll Cardiol 66:2451-2466

9. Connors LH, Sam F, Skinner M, Salinaro F, Sun F, Ruberg FL, Berk JL, Seldin DC (2016) Heart failure resulting from age-related cardiac amyloid disease associated with wild-type transthyretin: a prospective, observational cohort study. Circulation 133:282-290

10. Galat A, Guellich A, Bodez D, Slama M, Dijos M, Zeitoun DM, Milleron O, Attias D, Dubois-Rande JL, Mohty D, Audureau E, Teiger E, Rosso J, Monin JL, Damy T (2016) Aortic stenosis and transthyretin cardiac amyloidosis: the chicken or the egg? Eur Heart J 37:3525-3531

11. Tanskanen M, Peuralinna T, Polvikoski T, Notkola IL, Sulkava R, Hardy J, Singleton A, Kiuru-Enari S, Paetau A, Tienari PJ, Myllykangas L (2008) Senile systemic amyloidosis affects 25\% of the very aged and associates with genetic variation in alpha2macroglobulin and tau: a population-based autopsy study. Ann Med 40:232-239

12. Ruberg FL, Berk JL (2012) Transthyretin (TTR) cardiac amyloidosis. Circulation 126:1286-1300

13. Sperry BW, Vranian MN, Hachamovitch R, Joshi H, Ikram A, Phelan D, Hanna M (2016) Subtype-specific interactions and prognosis in cardiac amyloidosis. J Am Heart Assoc 5:e002877

14. Ng B, Connors LH, Davidoff R, Skinner M, Falk RH (2005) Senile systemic amyloidosis presenting with heart failure: a comparison with light chain-associated amyloidosis. Arch Intern Med 165:1425-1429

15. Wechalekar AD, Gillmore JD, Hawkins PN (2016) Systemic amyloidosis. Lancet 387:2641-2654

16. Falk RH (2011) Cardiac amyloidosis: a treatable disease, often overlooked. Circulation 124:1079-1085

17. Sayed RH, Rogers D, Khan F, Wechalekar AD, Lachmann HJ, Fontana M, Mahmood S, Sachchithanantham S, Patel K, Hawkins PN, Whelan CJ, Gillmore JD (2015) A study of implanted cardiac rhythm recorders in advanced cardiac AL amyloidosis. Eur Heart J 36:1098-1105

18. Gertz MA, Comenzo R, Falk RH, Fermand JP, Hazenberg BP, Hawkins PN, Merlini G, Moreau P, Ronco P, Sanchorawala V, Sezer O, Solomon A, Grateau G (2005) Definition of organ involvement and treatment response in immunoglobulin light chain amyloidosis (AL): a consensus opinion from the 10th International Symposium on Amyloid and Amyloidosis, Tours, France, 18-22 April 2004. Am J Hematol 79:319-328

19. Dahlem K, Michels G, Kobe C, Bunck AC, Ten Freyhaus H, Pfister R (2017) Diagnosis of cardiac transthyretin amyloidosis based on multimodality imaging. Clin Res Cardiol 106:471-473

20. Fritschka M, Schlegl M, Borges A, Werner M, Gebker R, Pieske B, Kelle S (2017) Unusual case of ATTR amyloidosis with cardiac manifestation and situs inversus totalis. Clin Res Cardiol 106:311-316 
21. Dispenzieri A, Gertz MA, Kyle RA, Lacy MQ, Burritt MF, Therneau TM, Greipp PR, Witzig TE, Lust JA, Rajkumar SV, Fonseca R, Zeldenrust SR, McGregor CG, Jaffe AS (2004) Serum cardiac troponins and $\mathrm{N}$-terminal pro-brain natriuretic peptide: a staging system for primary systemic amyloidosis. J Clin Oncol 22:3751-3757

22. Grogan M, Scott CG, Kyle RA, Zeldenrust SR, Gertz MA, Lin G, Klarich KW, Miller WL, Maleszewski JJ, Dispenzieri A (2016) Natural history of wild-type transthyretin cardiac amyloidosis and risk stratification using a novel staging system. J Am Coll Cardiol 68:1014-1020

23. Narang R, Cleland JG, Erhardt L, Ball SG, Coats AJ, Cowley AJ, Dargie HJ, Hall AS, Hampton JR, Poole-Wilson PA (1996) Mode of death in chronic heart failure. A request and proposition for more accurate classification. Eur Heart J 17:1390-1403

24. Rickenbacher P, Pfisterer M, Burkard T, Kiowski W, Follath F, Burckhardt D, Schindler R, Brunner-La Rocca HP, Investigators T-C (2012) Why and how do elderly patients with heart failure die? Insights from the TIME-CHF study. Eur J Heart Fail 14:1218-1229

25. Maurer MS, Schwartz JH, Gundapaneni B, Elliott PM, Merlini G, Waddington-Cruz M, Kristen AV, Grogan M, Witteles R, Damy T, Drachman BM, Shah SJ, Hanna M, Judge DP, Barsdorf AI, Huber P, Patterson TA, Riley S, Schumacher J, Stewart M, Sultan MB, Rapezzi C, Investigators A-AS (2018) Tafamidis treatment for patients with transthyretin amyloid cardiomyopathy. N Engl J Med 379:1007-1016

26. Vaduganathan M, Patel RB, Michel A, Shah SJ, Senni M, Gheorghiade M, Butler J (2017) Mode of death in heart failure with preserved ejection fraction. J Am Coll Cardiol 69:556-569

27. Siepen FAD, Bauer R, Voss A, Hein S, Aurich M, Riffel J, Mereles D, Rocken C, Buss SJ, Katus HA, Kristen AV (2018) Predictors of survival stratification in patients with wild-type cardiac amyloidosis. Clin Res Cardiol 107:158-169

28. Mohty D, Pradel S, Magne J, Fadel B, Boulogne C, Petitalot V, Raboukhi S, Darodes N, Damy T, Aboyans V, Jaccard A (2017) Prevalence and prognostic impact of left-sided valve thickening in systemic light-chain amyloidosis. Clin Res Cardiol 106:331-340
29. Brenner DA, Jain M, Pimentel DR, Wang B, Connors LH, Skinner M, Apstein CS, Liao R (2004) Human amyloidogenic light chains directly impair cardiomyocyte function through an increase in cellular oxidant stress. Circ Res 94:1008-1010

30. Kristen AV, Dengler TJ, Hegenbart U, Schonland SO, Goldschmidt H, Sack FU, Voss F, Becker R, Katus HA, Bauer A (2008) Prophylactic implantation of cardioverter-defibrillator in patients with severe cardiac amyloidosis and high risk for sudden cardiac death. Heart Rhythm 5:235-240

31. Lin G, Dispenzieri A, Kyle R, Grogan M, Brady PA (2013) Implantable cardioverter defibrillators in patients with cardiac amyloidosis. J Cardiovasc Electrophysiol 24:793-798

32. Feng D, Edwards WD, Oh JK, Chandrasekaran K, Grogan M, Martinez MW, Syed IS, Hughes DA, Lust JA, Jaffe AS, Gertz MA, Klarich KW (2007) Intracardiac thrombosis and embolism in patients with cardiac amyloidosis. Circulation 116:2420-2426

33. Roberts WC, Waller BF (1983) Cardiac amyloidosis causing cardiac dysfunction: analysis of 54 necropsy patients. Am J Cardiol 52:137-146

34. Adams D, Gonzalez-Duarte A, O'Riordan WD, Yang CC, Ueda M, Kristen AV, Tournev I, Schmidt HH, Coelho T, Berk JL, Lin KP, Vita G, Attarian S, Plante-Bordeneuve V, Mezei MM, Campistol JM, Buades J, Brannagan TH 3rd, Kim BJ, Oh J, Parman Y, Sekijima Y, Hawkins PN, Solomon SD, Polydefkis M, Dyck PJ, Gandhi PJ, Goyal S, Chen J, Strahs AL, Nochur SV, Sweetser MT, Garg PP, Vaishnaw AK, Gollob JA, Suhr OB (2018) Patisiran, an RNAi therapeutic, for hereditary transthyretin amyloidosis. $\mathrm{N}$ Engl J Med 379:11-21

35. Benson MD, Waddington-Cruz M, Berk JL, Polydefkis M, Dyck PJ, Wang AK, Plante-Bordeneuve V, Barroso FA, Merlini G, Obici L, Scheinberg M, Brannagan TH 3rd, Litchy WJ, Whelan C, Drachman BM, Adams D, Heitner SB, Conceicao I, Schmidt HH, Vita G, Campistol JM, Gamez J, Gorevic PD, Gane E, Shah AM, Solomon SD, Monia BP, Hughes SG, Kwoh TJ, McEvoy BW, Jung SW, Baker BF, Ackermann EJ, Gertz MA, Coelho T (2018) Inotersen treatment for patients with hereditary transthyretin amyloidosis. N Engl J Med 379:22-31 